\title{
Whose nose does not know? Demographical characterization of people unaware of anosmia
}

\author{
Anna Oleszkiewicz ${ }^{1,2}$ (1) $\cdot$ Thomas Hummel $^{1}$ \\ Received: 13 March 2019 / Accepted: 21 March 2019 / Published online: 15 April 2019 \\ (c) The Author(s) 2019
}

\begin{abstract}
Purpose For functionally anosmic subjects, the sense of smell is basically useless in daily activities-they are unlikely to detect the threatening smell of rotten food, gas or smoke, or to enjoy the flavor of food or the smell of perfumes. Although this appears very distressing, functionally anosmic subjects in our sample seemed not to be aware or bothered with impaired olfaction and enrolled for the study targeted to people with a normal sense of smell.

Methods In the large sample of 9139 subjects who declared themselves to have a normal sense of smell, we have retrospectively found a notable proportion of scores indicating functional anosmia.

Results When we look at the overall Sniffin' Sticks score, $0.45 \%$ of the sample was functionally anosmic and this fraction increased to $3.4 \%$ when the identification score of 8 points and below was used. We present demographical information of those subjects, who despite their inability to use smell in daily life, consider themselves healthy.

Conclusions Data offer a new perspective on the importance of olfaction in daily life and supports the notion about the importance of using screening tools in clinical practice.
\end{abstract}

Keywords Olfaction $\cdot$ Anosmia $\cdot$ Normosmia $\cdot$ Psychology $\cdot$ Smell

\section{Introduction}

The updated Sniffin' Sticks normative dataset [1] revealed a notable proportion of subjects whose score indicates functional anosmia despite the fact that all of them reported normal olfactory function.

The sample we utilized included only subjects who considered themselves healthy and reported a normal sense of smell. Importantly, the cohort we have been working with was relatively young (4928 females aged 5-96 years ( $M=31.8, \mathrm{SD}=18.9$ years) and 4211 males aged 5-91 years ( $M=30.7, \mathrm{SD}=17.7$ years) with $50 \%$ of the sample being younger than 25 years and $95 \%$ of the sample being younger

This comment refers to the article available at: https://doi. org/10.1007/s00405-018-5248-1.

Anna Oleszkiewicz

ania.oleszkiewicz@gmail.com

1 Smell and Taste Center, Department of Otorhinolaryngology, TU Dresden, Fetscherstrasse 74, 01307 Dresden, Germany

2 Institute of Psychology, University of Wroclaw, ul. Dawda 1, 50527 Wroclaw, Poland than 68 years. Based on the combined score of odor threshold, odor discrimination and odor identification subtests, we found $0.45 \%$ subjects with results of 16 points and below suggesting functional anosmia $(n=15 ; 5$ females aged between 79-90 years $M=84.2, \mathrm{SD}=4.1$ years, and 10 males aged $44-89$ years, $M=71.3, \mathrm{SD}=14.7$ years of the total number of 3356 individuals with the complete TDI score). This fraction increased to $3.4 \%$ when the identification score of 8 points and below was used to define functional anosmia ( $n=310$ of the total number of 8348 individuals with a score in the odor identification task only [note: throughout the text functional anosmia is referred to as "anosmia"]). For all these subjects, the sense of smell was basically useless in daily activities - they are unlikely to detect the threatening smell of rotten food, gas or smoke, or to enjoy the flavor of food or the smell of perfumes. But still they seemed not to be bothered with it and reported a normal sense of smell.

The criterion for functional anosmia based on the odor identification test only revealed that decreased odor identification ability was more frequent among females, who were significantly older than men, $t(308)=2.53, p=0.01$ - see Table 1. 
Table 1 Demographical characteristic of males and females being unaware of their functional anosmia-based on identification score of 8 points and below

\begin{tabular}{lll}
\hline & Female & Male \\
\hline$N$ & 190 & 120 \\
Age $M$ [in years] & 55.7 & 46.7 \\
Age SD & 31.6 & 28.6 \\
Age min & 6 & 5 \\
Age max & 96 & 91 \\
Smokers & 3 & 8 \\
\hline
\end{tabular}

Figure 1 presents the distribution of scores plotted against the age of male and female subjects. The issue of anosmia unawareness does not simply reflect a parabolic distribution-the prevalence of identification scores of 8 points and below among males and females was highest in youngest and oldest age groups, yet it is notable also in the middle-aged subjects who normally are at the height of their olfactory capabilities [2, 3]—-see Fig. 1.

Data further supports the notion that despite self-reported normal olfaction, severe olfactory impairment is present in a considerable proportion of subjects of all ages [4-6]. It can be argued that females generally outperform males in olfactory tasks [7-9] and that female's behavior and decisions are influenced by odors to a larger extent than male's $[10,11]$, yet further investigation targeted into variables explaining occurrence of unconscious functional anosmia is required.

Based on identification score of 8 points or less, anosmia was found to be more frequent in females than in males. In addition, an impaired ability to recognize odors also occurs among younger subjects (i.e., children, adolescents and young adults) as compared to deteriorated overall olfactory function (TDI score of 16 points and below). Various medical (e.g., history of infections, head trauma) and psychological conditions including cognitive deterioration resulting from aging and disrupted emotional processes like depression $[5,12]$ may explain the decreased ability to recognize commonly known odors. Of note, among anosmic subjects only very few were smokers. Although negatively related with overall olfactory performance [13], cigarette smoking is not common among subjects unaware of their functional anosmia [14].

Our findings support the argument for using screening tools for olfactory assessment in clinical practice. Surprisingly, a number of subjects consider themselves healthy and seem not to be bothered by the practical inability to smell. Thus, there is a considerable risk of false-negative diagnosis, especially in older people, when the diagnosis is based primarily on the medical interview including self-reported olfactory performance. Putting aside possible etiology, the absence of the sense of smell can cause a deterioration in the quality of life [15-18] which patients might have difficulties

\section{Functional anosmia unawareness}

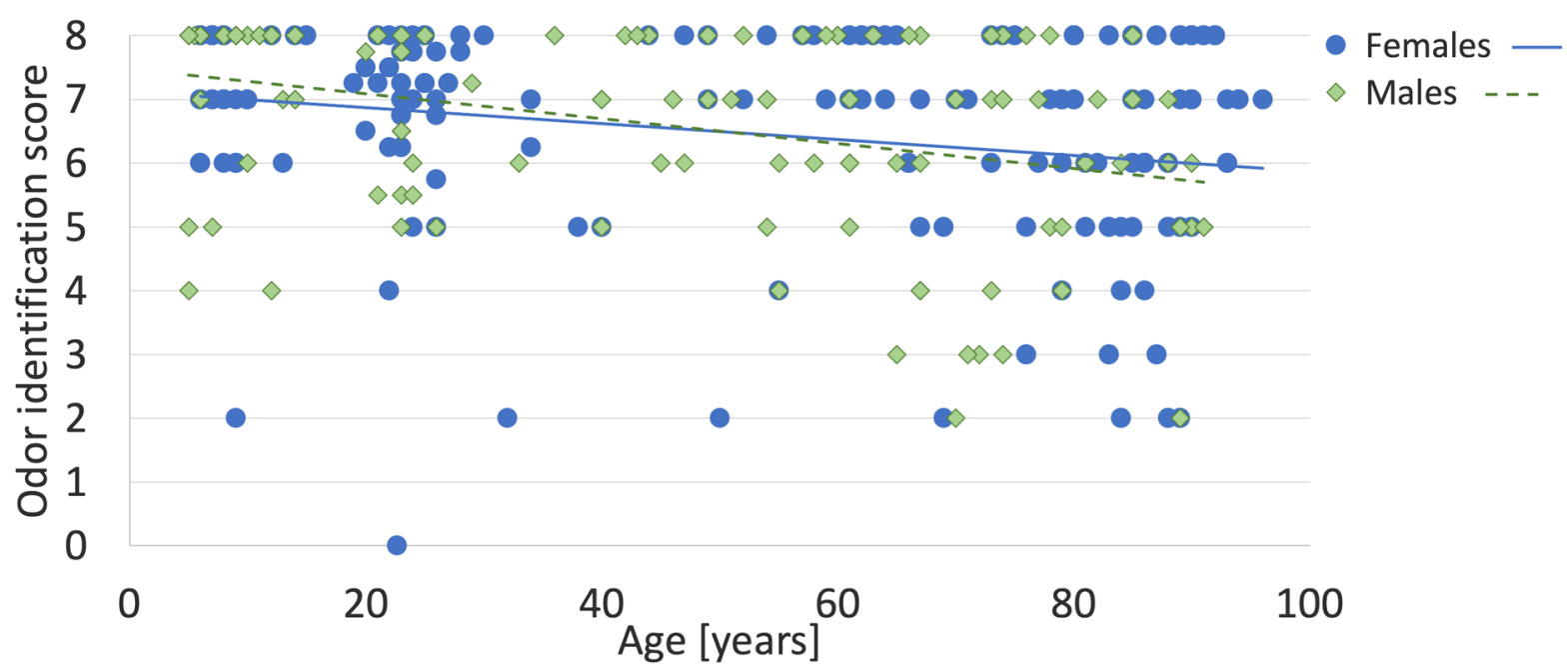

\begin{tabular}{|c|c|c|c|c|c|c|c|c|c|}
\hline Age [years] & $5-10$ & $11-20$ & $21-30$ & $31-40$ & $41-50$ & $51-60$ & $61-70$ & $71-80$ & $80+$ \\
\hline Number of functionally anosmic individuals & 45 & 19 & 48 & 10 & 15 & 20 & 32 & 38 & 83 \\
\hline$\%$ of to age category & $7 \%$ & $1.4 \%$ & $1.7 \%$ & $0.9 \%$ & $1.8 \%$ & $2.7 \%$ & $6.9 \%$ & $18 \%$ & $58 \%$ \\
\hline
\end{tabular}

Fig. 1 Prevalence of functional anosmia among male and female subjects declaring no olfactory impairment. Table at the bottom presents the number and fraction of individuals unaware of functional anosmia across the nine age groups 
to attribute to a certain health problem. As a consequence, they will not aim to undertake an adequate treatment. The latter argument should be of particular interest for psychologists and psychiatrists.

Scientists have no doubts that olfaction is of great importance for human interpersonal relationships and mating [19-22], regulation of emotions and behavior [23-25], learning and cognitive processes [26-28]. Functionality of olfactory system is profoundly associated with Parkinson's disease [29-31], Alzheimer's disease [32-34], and depression $[35,36]$. Presented evidence provokes a speculation that olfaction does not affect professional lives in most people and is not disabling itself. For instance, some patients with congenital anosmia do not notice the absence of smell in their lives and do not complain about it. Elderly subjects, whose sense of smell deteriorates gradually as a function of age, also find a way to cope with the inability to perceive odors. These observed examples speak against our common thinking of the sense of smell as a necessary condition for good health and satisfying life and urges to put the meaning of human olfaction into perspective [37]. Counterarguments could have their source in the more detailed social and psychosomatic characterization of people unaware or not bothered by anosmia and those who cannot smell yet are still convinced they can.

An important limitation of the current investigation is an uncontrolled comprehension and attention paid to the task by the subjects that could potentially translate into a low score. Although the Sniffin' Sticks examination was performed by well-trained staff at the Smell and Taste Center, assuring experience, clear instructions and additional explanations to the subjects if needed, we cannot rule out that some of the subjects with very low scores had difficulties to comprehend the task. However, the identification task being the simplest of the three Sniffin' Sticks tasks and usually the most engaging produced $3.4 \%$ of scores in the range of functional anosmia in subjects of various age.

Funding AO was supported by the Ministry of Science and Higher Education (\#626/STYP/12/2017); TH received support from the Deutsche Forschungsgemeinschaft (DFG HU411/18-1).

\section{Compliance with ethical standards}

Conflict of interest The authors have no conflict of interest to disclose.

Ethical approval The study was performed in accordance with the Declaration of Helsinki on Biomedical Studies Involving Human Subjects. The data included were gathered from studies in healthy controls performed over the last 20 years, all of which have been approved individually by the local Ethics Review Board.
Informed consent Informed written consent was obtained from all adult participants and children gave their assent to participate in a study.

Open Access This article is distributed under the terms of the Creative Commons Attribution 4.0 International License (http://creativeco mmons.org/licenses/by/4.0/), which permits unrestricted use, distribution, and reproduction in any medium, provided you give appropriate credit to the original author(s) and the source, provide a link to the Creative Commons license, and indicate if changes were made.

\section{References}

1. Oleszkiewicz A, Schriever VA, Croy I et al (2018) Updated Sniffin' Sticks normative data based on an extended sample of 9139 subjects. Eur Arch Oto Rhino Laryngol. https://doi.org/10.1007/ s00405-018-5248-1

2. Sorokowska A, Schriever VA, Gudziol V et al (2015) Changes of olfactory abilities in relation to age: odor identification in more than 1400 people aged 4 to 80 years. Eur Arch Oto Rhino Laryngol 272:1937-1944. https://doi.org/10.1007/s0040 5-014-3263-4

3. Doty R, Shaman P, Applebaum S et al (1984) Smell identification ability: changes with age. Science 226:1441-1443. https:// doi.org/10.1126/science.6505700

4. Wehling E, Lundervold AJ, Espeset T et al (2015) Even cognitively well-functioning adults are unaware of their olfactory dysfunction: implications for ENT clinicians and researchers. Rhinology 53:89-94. https://doi.org/10.4193/Rhin14.081

5. Croy I, Nordin S, Hummel T (2014) Olfactory disorders and quality of life-an updated review. Chem Senses 39:185-194. https://doi.org/10.1093/chemse/bjt072

6. Doty RL, Bromley SM (2003) Anosmia, ageusia, and other disorders of chemosensation. In: Brandt T, Dichgans J, Kennard C, et al. (eds) Neurological disorders: course and treatment, 2nd edn. Academic Press, New York, pp 171-183

7. Sorokowski P, Karwowski M, Misiak M et al (2019) Sex differences in human olfaction: a meta-analysis. Front Psychol 10:242. https://doi.org/10.3389/FPSYG.2019.00242

8. Brand G, Millot J (2001) Sex differences in human olfaction: between evidence and enigma. Q J Exp Psychol Sect B 54:259270. https://doi.org/10.1080/713932757

9. Doty RL, Applebaum S, Zusho H, Settle RG (1985) Sex differences in odor identification ability: a cross-cultural analysis. Neuropsychologia 23:667-672. https://doi.org/10.1016/00283932(85)90067-3

10. Herz RS, Inzlicht M (2002) Sex differences in response to physical and social factors involved in human mate selection: the importance of smell for women. Evol Hum Behav 23:359-364. https://doi.org/10.1016/S1090-5138(02)00095-8

11. Croy I, Buschhüter D, Seo H-S et al (2010) Individual significance of olfaction: development of a questionnaire. Eur Arch Oto Rhino Laryngol 267:67-71. https://doi.org/10.1007/s00405-009-1054-0

12. Frasnelli J, Hummel T (2005) Olfactory dysfunction and daily life. Eur Arch Oto Rhino Laryngol 262:231-235. https://doi. org/10.1007/s00405-004-0796-y

13. Vennemann M, Hummel T, Berger K (2008) The association between smoking and smell and taste impairment in the general population. J Neurol 255:1121-1126. https://doi.org/10.1007/ s00415-008-0807-9

14. Philpott CM, Wolstenholme CR, Goodenough PC et al (2007) Which variables matter in smell tests in the clinic? J Laryngol Otol 121:952-956. https://doi.org/10.1017/S0022215107006408 
15. Croy I, Landis BN, Meusel T et al (2011) Patient adjustment to reduced olfactory function. Arch Otolaryngol Head Neck Surg 137:377-382. https://doi.org/10.1001/archoto.2011.32

16. Mattos JL, Schlosser RJ, Storck KA, Soler ZM (2017) Understanding the relationship between olfactory-specific quality of life, objective olfactory loss, and patient factors in chronic rhinosinusitis. Int Forum Allergy Rhinol 7:734-740. https://doi. org/10.1002/alr.21940

17. Hummel T, Nordin S (2005) Olfactory disorders and their consequences for quality of life. Acta Otolaryngol 125:116-121. https://doi.org/10.1080/00016480410022787

18. Shu CH, Lee PO, Lan MY, Lee YL (2011) Factors affecting the impact of olfactory loss on the quality of life and emotional coping ability. Rhinology 49:337-341. https://doi.org/10.4193/ Rhino10.130

19. Russell MJ (1976) Human olfactory communication. Nature 260:520-522. https://doi.org/10.1038/260520a0

20. Havlicek J, Saxton TK, Roberts SC et al (2008) He sees, she smells? Male and female reports of sensory reliance in mate choice and non-mate choice contexts. Pers Individ Differ 45:565570. https://doi.org/10.1016/j.paid.2008.06.019

21. Roberts SC, Kralevich A, Ferdenzi C et al (2011) Body odor quality predicts behavioral attractiveness in humans. Arch Sex Behav 40:1111-1117. https://doi.org/10.1007/s10508-011-9803-8

22. Ferdenzi C, Schaal B, Roberts SC (2010) Family scents: developmental changes in the perception of kin body odor? J Chem Ecol 36:847-854. https://doi.org/10.1007/s10886-010-9827-x

23. Bensafi M, Iannilli E, Schriever VA et al (2013) Cross-modal integration of emotions in the chemical senses. Front Hum Neurosci 7:883. https://doi.org/10.3389/fnhum.2013.00883

24. Lemogne C, Smadja J, Zerdazi E-H et al (2015) Congenital anosmia and emotion recognition: a case-control study. Neuropsychologia 72:52-58. https://doi.org/10.1016/J.NEUROPSYCHOLOGI A.2015.04.028

25. Ehrlichman H, Bastone L (1992) Olfaction and emotion. Science of olfaction. Springer, New York, pp 410-438

26. Willander J, Larsson M (2006) Smell your way back to childhood: autobiographical odor memory. Psychon Bull Rev 13:240-244. https://doi.org/10.3758/BF03193837

27. Willander J, Larsson M (2007) Olfaction and emotion: the case of autobiographical memory. Mem Cognit 35:1659-1663. https ://doi.org/10.3758/BF03193499
28. Herz RS, Schankler C, Beland S (2004) Olfaction, emotion and associative learning: effects on motivated behavior. Motiv Emot 28:363-383. https://doi.org/10.1007/s11031-004-2389-x

29. Haehner A, Hummel T, Hummel C et al (2007) Olfactory loss may be a first sign of idiopathic Parkinson's disease. Mov Disord 22:839-842

30. Haehner A, Hummel T, Reichmann H (2009) Olfactory dysfunction as a diagnostic marker for Parkinson's disease. Expert Rev Neurother 9:1773-1779. https://doi.org/10.1586/ern.09.115

31. Mesholam RI, Moberg PJ, Mahr RN et al (1998) Olfaction in neurodegenerative disease. Arch Neurol 55:84. https://doi. org/10.1001/archneur.55.1.84

32. Rahayel S, Frasnelli J, Joubert S (2012) The effect of Alzheimer's disease and Parkinson's disease on olfaction: a metaanalysis. Behav Brain Res 231:60-74. https://doi.org/10.1016/J. BBR.2012.02.047

33. Serby M, Larson P, Kalkstein D (1991) The nature and course of olfactory deficits in Alzheimer's disease. Am J Psychiatry 148:357-360

34. Larsson M, Semb H, Winbald B et al (1999) Odor identification in normal aging and early Alzheimer's disease: effects of retrieval support. Neuropsychology 13:47-53

35. Negoias S, Croy I, Gerber J et al (2010) Reduced olfactory bulb volume and olfactory sensitivity in patients with acute major depression. Neuroscience 169:415-421. https://doi.org/10.1016/j. neuroscience.2010.05.012

36. Negoias S, Hummel T, Symmank A et al (2016) Olfactory bulb volume predicts therapeutic outcome in major depression disorder. Brain Imaging Behav 10:367-372. https://doi.org/10.1007/s1168 2-015-9400-x

37. McGann JP (2017) Poor human olfaction is a 19th-century myth. Science 356:7263. https://doi.org/10.1126/science.aam7263

Publisher's Note Springer Nature remains neutral with regard to jurisdictional claims in published maps and institutional affiliations. 